University of Nebraska - Lincoln

DigitalCommons@University of Nebraska - Lincoln

Faculty Publications from the Harold W. Manter Laboratory of Parasitology

$12-1997$

\title{
Evolution of the Schistosomes (Digenea: Schistosomatoidea): The Origin of Dioecy and Colonization of the Venous System
}

Thomas R. Platt

St. Mary's College

Daniel R. Brooks

University of Toronto,dnlbrooks@gmail.com

Follow this and additional works at: https://digitalcommons.unl.edu/parasitologyfacpubs

Part of the Parasitology Commons

Platt, Thomas R. and Brooks, Daniel R., "Evolution of the Schistosomes (Digenea: Schistosomatoidea): The Origin of Dioecy and Colonization of the Venous System" (1997). Faculty Publications from the Harold W. Manter Laboratory of Parasitology. 229.

https://digitalcommons.unl.edu/parasitologyfacpubs/229

This Article is brought to you for free and open access by the Parasitology, Harold W. Manter Laboratory of at DigitalCommons@University of Nebraska - Lincoln. It has been accepted for inclusion in Faculty Publications from the Harold W. Manter Laboratory of Parasitology by an authorized administrator of DigitalCommons@University of Nebraska - Lincoln. 


\title{
EVOLUTION OF THE SCHISTOSOMES (DIGENEA: SCHISTOSOMATOIDEA): THE ORIGIN OF DIOECY AND COLONIZATION OF THE VENOUS SYSTEM
}

\author{
Thomas R. Platt and Daniel R. Brooks $\uparrow$ \\ Department of Biology, Saint Mary's College, Notre Dame, Indiana 46556
}

\begin{abstract}
Trematodes of the family Schistosomatidae are considered venous system specialists whose sister group is the vascular system generalists (Spirorchidae) of turtles. Colonization of homeotherms by vascular trematodes required precision egg laying near the conduit for egg passage to the external environment and avoidance of pathogenesis that might result in the premature death of the host. Evolution of dioecy from the hermaphroditic condition may have proceeded through androdioecy in which hermaphrodites were specialized for precision egg placement in the vascular system and larger adults became functional males. The evolution of nuclear genes suppressing female function along with cytoplasmic genes suppressing male function could then have resulted in the origin of dioecious, dimorphic populations. Schistosomes compensated for the reduction in potential reproductive partners by (1) increased overdispersion in the vertebrate host, (2) reduced egg hatching time in the external environment, (3) formation of permanent pairs mimicking the hermaphroditic condition, (4) increased longevity in the definitive host, and (5) increased fecundity. Colonization of the venous system was necessitated by (1) evolutionary radiation into terrestrial vertebrates and (2) the increased immunopathology associated with the high, constant body temperature of homeothermic vertebrates. The immune response to spirorchid and schistosome eggs appears to be qualitatively similar in their respective hosts. The arterial dwelling spirorchids release eggs in the direction of blood flow, resulting in a wide dissemination of eggs within the host. The lower body temperature of poikilotherms accompanied by the seasonal nature of the immune response in these hosts would result in a quantitatively reduced pathogenesis. Hosts that did succumb to the infection would most likely die in water, where eggs could be released by predation, scavengers, or decomposition and develop successfully. Colonization of the venous system by schistosomes would require precision egg placement because eggs are released against blood flow. Eggs are sequestered within the portal system of homeotherms, thus restricting egg dispersal and resulting pathogenesis to less sensitive organs. A significant number of eggs may escape into the external environment before a heavily infected host is incapacitated by, or dies from, the infection.
\end{abstract}

The schistosomes (Digenea: Schistosomatidae), because of their importance as human pathogens, are the most thoroughly studied digenetic trematodes. Despite the enormous effort made to understand the immunology, biochemistry, genetic structure, and life history of these debilitating helminths, little effort has been made to elucidate, or even speculate on, the evolution of this fascinating group of organisms. This is regrettable, though not surprising; as Brooks and McLennan (1993c) showed, little of parasite evolutionary biology postdates the orthogenesis movement of 1890-1940. The most puzzling aspect of schistosome biology is the evolution of the dioecious condition from hermaphroditic ancestors. Of the more than 100 nominal families ( $>10,000$ species) of digeneans described, only the Schistosomatidae (comprising approximately 100 species) are exclusively gonochoristic. Combes (1991) termed the failure to explain this evolutionary novelty a "scandal."

The advent of modern methods of phylogenetic analysis and historical ecology (Brooks and McLennan, 1991) has made it possible to investigate major patterns of parasite evolution within a rigorous framework (Brooks and McLennan, 1993c). Couching evolutionary hypotheses in explicit phylogenetic terms has been shown to be an effective way to suggest experimental studies designed to elucidate the mechanisms responsible for observed evolutionary patterns (e.g., McLennan, 1996). This should be as true for parasites as for free-living species because parasites, as a group, do not appear to exhibit any unique or distinctive pattern of evolutionary diversification (Brooks and McLennan, 1993a, 1993b, 1993c).

Received 26 February 1997; revised 14 May 1997; accepted 14 May 1997.

* Department of Zoology, University of Toronto, Toronto, Ontario, Canada M5S 1A1.

\section{SPIRORCHIDS AND SCHISTOSOMES}

The Superfamily Schistosomatoidea contains 3 families: Sanguinicolidae (fish), Spirorchidae (turtles), and Schistosomatidae (crocodilians, birds, and mammals). Life cycle and morphological data identify these 3 families as a monophyletic taxon, with the spirorchids the sister-group of the schistosomatids (Brooks et al., 1985, 1989). If the monoecious Spirorchidae is the sistergroup of the dioecious Schistosomatidae, we should look to the spirorchids for clues to the evolutionary history of the schistosomes.

Species of the Schistosomatoidea share commonalities in life history and transmission patterns. All have brevifurcate furcocercous cercariae that develop to sexual maturity following direct penetration of the definitive host (Yamaguti, 1975) and typically occupy the circulatory system as adults. Spirorchids may be considered vascular system generalists with a preference for the heart and arterial system of their chelonian hosts (Yamaguti 1971, 1975). Spirorchids have also been reported regularly from extravascular sites (Stunkard, 1923; Ulmer, 1959; Holliman et al., 1971; Brooks and Mayes, 1975; Brooks, 1979; Platt, 1993; T. Platt, pers. obs.). Conversely, schistosomes are venous specialists with the exception of Dendritobilharzia pulverulenta, which inhabits the mesenteric arteries of ducks (Vande Vusse, 1979).

The 2 major issues requiring explanation in schistosome evolution are the origins of dioecy and the colonization of the venous system. Placing these events in a coherent scenario necessitates a comparative examination of reproductive strategies of spirorchids and schistosomes as well as the immunological response to these helminths by poikilothermic and homeothermic hosts. Basch (1991) provided an extensive review of the morphology and reproductive biology of the schistosomes, and we refer the interested reader to that source for the pertinent literature in the ensuing discussion. 


\section{FROM HERMAPHRODITISM TO DIOECY}

The development of dioecy in schistosomes has been associated with the origin of endothermy (Grossman et al., 1981; Short, 1983), the development of the more sophisticated immune system present in endothermic vertebrates (Combes, 1991), or the shift from arterial to venous habitat accompanied by the development of the homeotherm portal system and subsequent colonization of terrestrial rather than primarily aquatic hosts (Basch, 1991). Chromosomal inversion and translocation have been invoked to derive the heterogametic schistosome karyotype from the homogametic karyotypes found in spirorchids (Grossman et al., 1981; Short, 1983) although "presex" chromosomes were reported in a small number of spirorchid cell preparations (Grossman et al., 1981). Basch (1991) concluded that the chromosomal changes accompanied, but did not cause, the transition from hermaphrodite to gonorchist. Dioecy must be considered an apomorphic trait in the schistosomes because the spirorchids and all other members of the Strigeiformes (sensu Brooks et al., 1985, 1989) are hermaphroditic. Several species of schistosomes demonstrate the atavistic capacity to develop as hermaphrodites (Basch, 1991). Males tend to develop more nearly complete female systems than the reverse although the subordinate gender does not appear to develop completely and produce fully functional hermaphrodites (Basch, 1991).

The discovery of Griphobilharzia amoena from the Australian freshwater crocodile (Platt et al., 1991) suggests that dioecy preceded the origin of homeothermy although it is possible this represents a secondary transfer from an avian or mammalian host. Separation of the genders in the schistosomes may be related to enhanced outcrossing during sexual reproduction. All hermaphroditic digeneans cross-fertilize in groups although most species self-inseminate in single-worm infections (Nollen, 1983; Fried, 1986). Rates of self-insemination in group infections vary (Nollen, 1983). Experiments with single- and multiple-worm infections are equivocal with respect to long-term selfing. Some species produce viable eggs or offspring that fail to mature, whereas some reproduce for 1 or 2 generations before showing reduced fertility or rates of establishment (Nollen, 1983). Prevention of self-insemination, at any level, increases genetic diversity if, either through transmission patterns or mate selection, pairing of nonsiblings is the rule rather than the exception (Read and Nee, 1990). Combes (1991) suggested that separate genders would preclude any possibility of self-fertilization, thus maximizing genetic diversity and increased survival in the face of the development of the more sophisticated immune systems found in homeothermic vertebrates. Genetic profiles of individual Schistosoma mansoni demonstrated a diversity of parasite genotypes and indicated that over half of the infected Biomphalaria glabrata from Belo Horizonte, Brazil, were more likely to harbor multiple infections than expected by chance (Minchella et al., 1995). These authors concluded that the higher than expected rate of multiple infections in the intermediate host would aid in maintaining genetic diversity through out-crossing in the definitive host. Genetic diversity might also be increased by mate selection. Among schistosomes, interspecific pairing occurs (Tchuem Tchuenté et al., 1994; Southgate et al., 1995), but males mate preferentially with conspecifics in mixed infections (Tchuem Tchuenté et al.
1995); however, intraspecific mate preferences are unknown (Read and Nee, 1990). The results presented by Nollen (1983) and Fried (1986) above suggest that hermaphroditic digeneans possess mate-finding abilities, so it is not surprising to find that schistosomes also possess mate-finding capabilities. Whereas genetic diversity may be necessary to maintain successful populations, it is not sufficient to explain the origins of dioecy within the group.

Why should schistosomes abandon the clearly successful hermaphroditic life style? Dioecious parasitic platyhelminths are rare but occur among the Digenea, Monogenea, and Eucestoda and inhabit gills, intestines, and circulatory systems. It would appear that this is a rare event that is not habitat specific, that is, becoming dioecious is not an adaptation to a particular habitat. Consequently, we should ask what is lost and what is gained by the organisms themselves? Three models have been proposed to explain the evolution of hermaphroditism-low density, size advantage, and gene dispersal (Ghiselin, 1969; Clark, 1978). Clark (1978) refined the definition of hermaphroditism to include only "the occurrence together in a single individual of mature ova and sperm that originated within that individual, and which are potentially capable of either self- or cross-fertilization to give rise to a new individual." He termed this state euhermaphroditism. The low density and gene dispersal models (Ghiselin, 1969) would apply to this more narrow concept, whereas the size advantage model would be applicable to sequential hermaphroditism, e.g., protandry or protogyny, androdioecy, or gynodioecy. We examine each model in turn.

The low density model is most often applied to parasitic organisms. It suggests that euhermaphroditism will be common in organisms with low mobility or low population density, i.e., reduced mating opportunities (Ghiselin, 1969). Because schistosomes evolved from euhermaphroditic ancestors that successfully solved these problems, they retained traits (symplesiomorphies) that were instrumental in that success, e.g., asexual amplification in reproduction through the production of daughter sporocyts and cercariae and overdispersed distributions in the snail and vertebrate hosts. Anderson (1993) suggested that gonorchistic trematodes could overcome low-density effects by increasing overdispersion, increasing reproductive potential, and/or reducing the time required for development outside the host. Like other digeneans, schistosomes employ these strategies. The high, constant body temperature associated with homeotherms should also increase egg production over that found in poikilothermic hosts. Information on spirorchid reproductive potential is not available for comparative purposes. Differences in miracidial development and hatching also support Anderson's (1993) hypothesis. Schistosome eggs hatch within minutes of entering the aquatic environment (Basch, 1991), whereas spirorchid eggs require several days in the external environment before miracidial hatching occurs (Wall, 1941a, 1941b, 1951; Goodchild and Kirk, 1960; Holliman and Fisher, 1968; Holliman et al., 1971). Empirical data, limited to the $S$. mansoni/ Rattus rattus complex in Guadeloupe, suggest high levels of overdispersion ( $\mathrm{k}=0.1$; Théron et al., 1992). Increased adult longevity might also aid in overcoming low density effects by increasing reproductive capacity. Fulford et al. (1995) estimated a life span of 5.7-10.5 yr for $S$. mansoni in humans in Kenya. Again, lack of longevity data for spirorchids precludes a direct comparison. 
TABLE I. Comparison of the mean body widths of adult Sanguinicolidae, Schistosomatidae, and Spirochidae (Digenea).

\begin{tabular}{lcc}
\hline & $\mathrm{n}$ & $\bar{x}$ width $(\mu \mathrm{m})^{*}$ \\
\hline Spirorchid & 41 & $390^{\mathrm{a}}$ \\
Sanguinicolid & 47 & $580^{\mathrm{a}}$ \\
Schistosome (male) & 56 & $465^{\mathrm{a}}$ \\
Schistosome (female) & 56 & $187^{\mathrm{b}}$ \\
\hline
\end{tabular}

* Values with different superscripts are significantly different $(P<0.001)$. Data and references available from T.R.P. upon request.

The gene dispersal model includes 2 versions-inbreeding and sampling error (Ghiselin, 1969). Protandry and protogyny aid in reducing inbreeding because as each cohort matures, its members change reproductive roles and the likelihood of sib matings declines. Sampling error reduces the effects of genetic drift by producing a sex ratio in euhermaphroditic populations of 1:1. Evidence (Minchella et al., 1995) suggests that inbreeding may not be a problem for schistosomes and by mimicking the hermaphroditic condition (Clark, 1978), stable pair formation also effectively reduces the problem of sampling error by limiting the genetic contribution of any individual to the next generation. Ancient mate-finding abilities demonstrated by hermaphroditic digeneans (Nollen, 1983; Fried, 1986) and present in schistosomes would augment pair formation. In addition, available evidence suggests that the sex ratio of schistosomes is skewed toward males in cercarial production and within the definitive host (Basch, 1991). Because males appear to be the active partner in pair formation (Basch, 1991; Tchuem Tchuenté et al., 1995), maximal production of male cercariae, within the size and energetic constraints imposed by the snail host, would maximize individual fitness through clonal selection even though some males would remain unmated (Morand et al., 1993).

The size advantage model postulates a differential reproductive advantage with increased (or decreased) size associated with gender (Ghiselin, 1969). Precision egg laying in the schistosomes would necessitate a reduction in female width compared with their spirorchid counterparts. Maynard Smith (in Combes, 1991) suggested that the development of gonorchism might be related to precision egg placement by the female worm. If gonorchism is related to a division of labor associated with specialization in site selection for egg laying, we would predict that not only would female schistosomes be narrower than their male counterparts but female schistosomes would be significantly more slender than spirorchids. Length and width measurements for 54 schistosome species (16 genera) and 41 freshwater spirorchids ( 9 genera) were collected from the literature and compared statistically using the Mann-Whitney $U$ test (Jensen, 1996). As predicted, male schistosome width is not significantly different from spirorchid width, whereas females are significantly more slender (Table I). As a phylogenetic control, similar information was obtained for 47 species of sanguinicolids (15 genera), the sister-group of the spirorchids + schistosomes; sanguinicolids exhibit the same pattern as spirorchids, supporting the interpretation that the condition exhibited by schistosomes is the apomorphic (evolutionarily derived) condition (Table I). The preceding information does not provide a causal mechanism for dioecy, but it does suggest that female schistosomes show a change in body proportions suggestive of an adaptive response to favoring precision egg deposition.

Does the male schistosome have any function beyond fertilizing the female? Basch (1990) argued that in $S$. mansoni the loss of female musculature that permits precision egg laying is compensated for by the male. The male transports the female to the mesenteric venules from the liver and, subsequently, throughout the mesenteric circulation during egg-laying forays. Basch (1990) also suggested that muscle loss in the female extends to a poorly developed pharynx and an impaired ability to feed. The muscular action of the male is necessary for the female to acquire adequate nutrition. The male massages the female, stimulating pharyngeal action and the ingestion of red blood cells necessary for continued egg production.

It would appear schistosomes lost little by taking the road to gonorchism. Enhancement of overdispersion, characteristic of many parasite populations, would provide sufficient numbers of worms to ensure the presence of males and females in most hosts. Skewing the sex ratio toward excess males would ensure that all females would find a partner, multiple infections in the snail intermediate host would enhance genetic diversity associated with gonorchism, and long-term pairing would reduce the effects of genetic drift. The division of labor between robust males and slender females would strengthen the necessity of long-term pairing and provide the capacity for precision egg laying and enhanced escape of eggs from the circulatory system and into the external environment.

The preceding analysis indicates that the separation of genders in a hermaphroditic population of digenetic trematodes is not an insuperable problem and suggests plausible functional roles for the resulting individuals. It does not, however, identify environmental forces that might necessitate the ensuing habitat specialization, i.e., restriction to the venous system evident in the schistosomes.

\section{THE VENOUS SYSTEM, IMMUNITY, AND PATHOGENESIS}

There is no evidence to predict that the vascular system generalist spirorchids (see above) would give rise to a venous system specialist. It is possible that the ancestral species of schistosomes inhabited the venous system and that the ensuing radiation was the result of genetic drift via the founder effect. Because spirorchids primarily occupy the arterial system of turtles, the venous system represented an unoccupied and underutilized niche in the thecodonts and archosaurian reptiles. Simple mechanical differences between the turtles and homeotherms could have played a role in stimulating the shift to the venous system as well. Blood pressure in the right aorta and common pulmonary artery in turtles is half, or less than half (20-50 $\mathrm{mm} \mathrm{Hg}$ ), that found in birds and mammals (Burggren, 1987) and nearer the $5-10-\mathrm{mm} \mathrm{Hg}$ found in the portal veins of humans (Ganong, 1983). Maintaining position or migrating against the current in the arterial system of homeotherms might have been difficult or impossible. Individuals with a predilection for the venous system might have had a significant adaptive advantage over conspecifics with a preference for the arterial system. Wu and Wu (1986) demonstrated that fractionated portal serum contained elements in the 2,000-50,000 KDa fraction that significantly enhanced oviposition in $S$. mansoni. These unidentified components were present in the portal circulation 
of permissive and nonpermissive hosts but were absent in the peripheral serum of both. Increased egg output would provide a significant selection advantage and fulfill one of the criteria for gonorchism suggested by Anderson (1993).

An additional, but not mutually exclusive, explanation for venous specialization involves an examination of the pathological effects of blood fluke infection in poikilothermic and homeothermic vertebrates. Immune response to eggs is considered the primary source of pathogenesis in schistosome infections of humans (Warren, 1978). Whereas the pathogenic effects of spirorchids in turtles are much less well studied, the evidence suggests that the immune response to eggs is similar in poikilothermic and homeothermic hosts (Overstreet and Thulin, 1989).

Adult spirorchids and schistosomes are all subject to assault by the immune system. The manner of evasion of immune action has been well studied in the schistosomes; however, no information regarding this host-parasite interaction is available for spirorchids and their chelonian hosts. Most spirorchid and schistosome eggs must pass through the wall of the vascular system and either the intestinal or bladder wall before completing their development in the external environment. Eggs of those schistosome species that reside in the nasal circulation of birds and mammals are released, presumably, when the animal drinks or its head is submerged during feeding or diving.

Primary pathogenesis in mammalian schistosome infections is the result of a delayed hypersensitivity reaction to the eggs (Warren, 1978) resulting initially in granuloma formation and the development of pseudotubercles in chronic infections (Brown and Neva, 1983). The granulomas are composed primarily of eosinophils, plasma cells, neutrophils, and lymphocytes (Chen, 1993). Pathology to spirorchid eggs in chelonians is not as well documented, but the patterns are "strikingly similar to those seen in primates" (Wolke et al., 1982). The primary cell types differ slightly; lymphocytes, macrophages, giant cells, and few eosinophils predominate in turtle granulomas (Wolke et al., 1982; Glazebrook et al., 1989).

Johnson (1986), following conventional wisdom, listed schistosomiasis as an example of pathogenesis impeding transmission and reducing the reproductive success of both the host and parasite. Damian (1987) demonstrated elegantly that this is clearly not the case. Granuloma formation in response to the egg is necessary to transport the egg from the circulatory system to the lumen of the gut (Damian, 1987) or the urinary bladder. Although comparable studies are not available for the spirorchid/turtle system, we can assume from the similarities of the cellular response in turtles that eggs traversing the mucosa are transported by similar processes.

"Reptile immunology currently consists of a disparate body of information from many species investigated in a heterogeneous class of tetrapods" (Jurd, 1994). Therefore, comparisons of turtle and mammalian immune systems and responses will be limited. Cell-mediated and humoral immunity has been reported from all vertebrate classes (Borysenko, 1978) and turtles are no exception (Borysenko, 1978; Tizzard, 1992). Turtles produce 3 immunoglobins-IgM, IgY, and a possible homolog of IgA (Jurd, 1994). The first 2 have antibody function, and antibody response to a wide range of antigens has been demonstrated. Primary and secondary cell-mediated reactions have been reported from turtles (Borysenko, 1978), including graft rejection and delayed hypersensitivity reactions (Jurd, 1994).

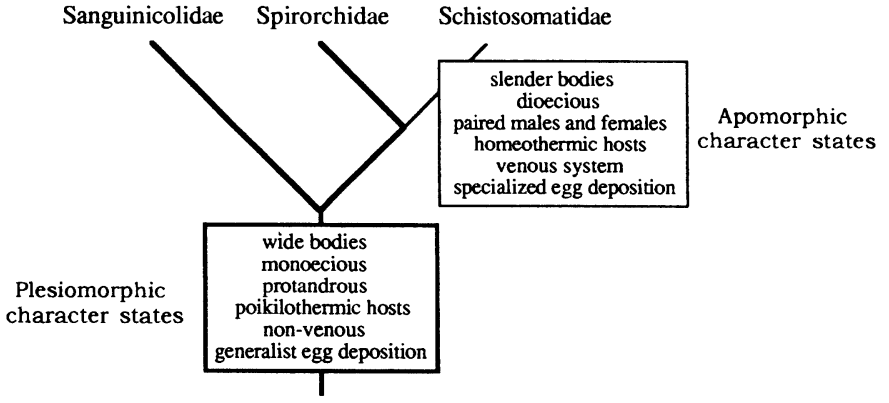

FIGURE 1. Phylogenetic tree depicting sister group relationships among the Sanguinicolidae, Spirorchidae, and Schistosomatidae. The box at the base of the tree includes the plesiomorphic (ancestral) conditions for 6 traits relevant to various theories about the evolution of dioecy in schistosomes. The box associated with the branch of the tree for the Schistosomatidae includes the apomorphic (derived) conditions for those 6 traits. At this level of phylogenetic resolution, we cannot assign any particular characters priority in scenarios about the evolution of dioecy. Nor can we detect the presence of any intermediate steps between protandrous hermaphroditism and dioecy.

The immune systems of poikilothermic amniotes demonstrate significant seasonal changes in both structure and function $(\mathrm{Za}-$ pata et al., 1992). Development of lymphoid tissue and immune reactivity reach their peak in late spring and early summer, declining in late summer through early spring. Whereas these changes in neuroendocrine function are endogenous, seasonal changes in photoperiod and temperature are thought to affect corticosteroid production, with high levels of cortisol and corticosterone suppressing immune reactivity (Zapata et al., 1992). Therefore, although not equivalent to the immune responses in homeotherms, poikilothermic amniotes do possess sophisticated immunity (Jurd, 1994) capable of responding in similar fashion to the presence of antigens. Strong seasonal suppression of the neuroendocrine system should reduce the overall effect of cellmediated immunity and the extent of damage associated with delayed hypersensitivity reactions.

\section{EGG DEPOSITION AND PATHOLOGY}

On the basis of the previous discussion, we can assume that the delayed hypersensitivity reaction, though qualitatively similar in turtles and homeotherms, should result in greater pathogenesis in homeotherms because of the maintenance of a constant, high body temperature. Differential pathogenesis may well result in different egg-laying strategies between the spirorchids and schistosomes. Spirorchids demonstrate at least 2 different egg-laying strategies in the turtle. Many marine forms (e.g., Hapalotrema spp. and Learedius spp., and freshwater species (e.g., Spirorchis haematobium and Plasmiorchis spp.) are robust and are most commonly reported from the heart and major arteries (Smith, 1972). Eggs are released into the vascular current and carried downstream, where they lodge in the capillary beds of numerous organs (Goodchild and Dennis, 1967; Greiner et al., 1980; Wolke et al., 1982; Glazebrook et al., 1989) some distance from the presumptive site of release. Eggs of more slender forms (e.g., Spirorchis parvus) tend to remain close to the site of deposition and the adult worm (Wall, 1941a, 1941b; Holliman et al., 1971).

Almost all schistosomes occupy the venous system and, hence, deposit eggs against the direction of blood flow; preci- 

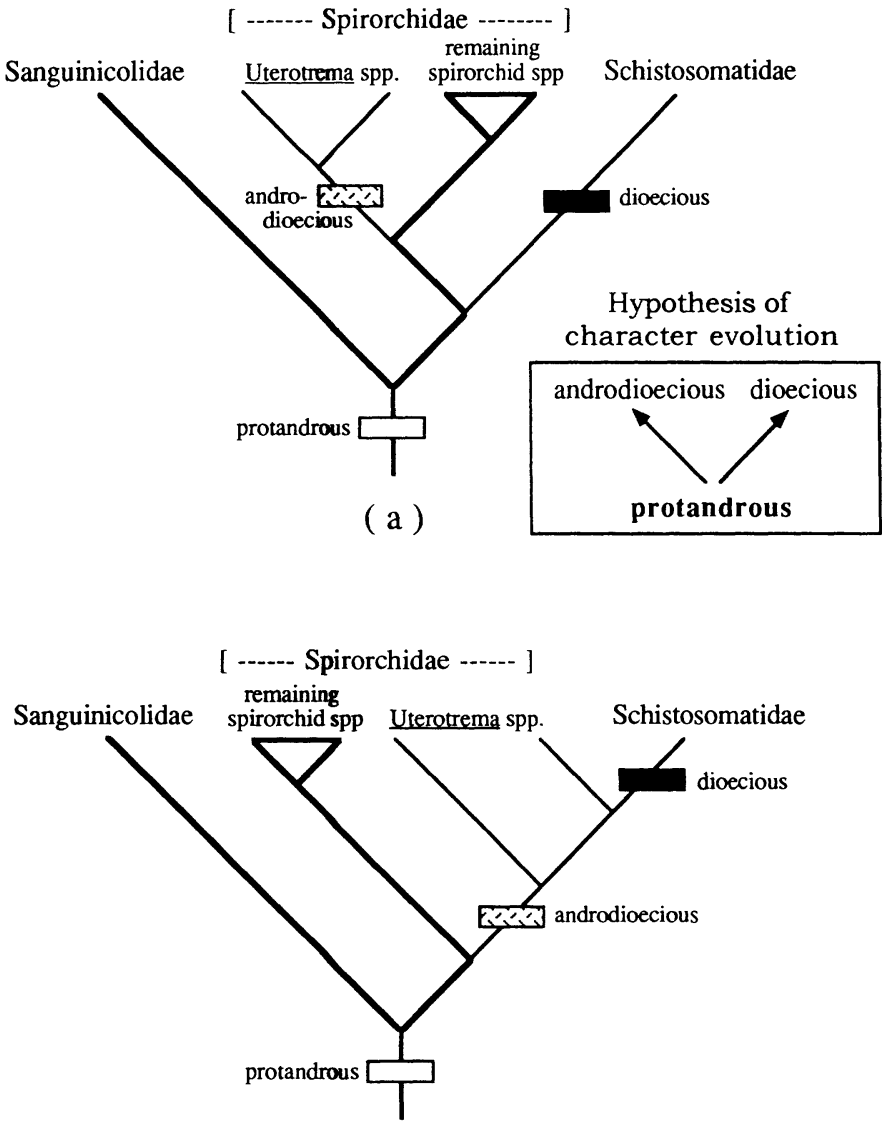

( b )

Hypothesis of

character evolution

protandrous $\longrightarrow$ androdioecious $\longrightarrow$ dioecious

FIGURE 2. Two hypothetical renderings of phylogenetic relationships among members of the Spirorchidae with respect to the Sanguinicolidae and Schistosomatidae. (a) Androdioecy in Uterotrema and dioecy in the Schistosomatidae each evolved independently from protandrous hermaphroditism (see box). (b) Androdioecy in Uterotrema is derived from protandrous hermaphroditism, and dioecy in the Schistosomatidae is derived from androdioecy (see box). For more explanation, see text.

sion placement, therefore, is critical to the successful passage of eggs to the external environment and to prevent the eggs from being swept into the portal circulation (Basch, 1991). Females migrate into the smallest venules, releasing eggs as they back up toward the male. The natural elasticity of the vessel serves to hold the egg in place against the flow of blood (Basch, 1991). Endothelial cells actively migrate over the egg and passively transfer the egg to the perivenular space (File, 1995), where they are subject to immune action. It is also possible that the male physically blocks the vessel, preventing recently deposited eggs from being dislodged until they are secured by endothelial cells.

Wood and Bacha (1983) examined the process of egg deposition and pathogenesis of Austrobilharzia variglandis in the mesenteric veins of domestic chickens. They observed paired adults in the mesenteric veins, or branches, paralleling the mesenteric border of the intestine. Females traveled from vessels in the serosa through the muscularis, squeezed into the small veins of the mucosa, and then withdrew back to the serosa following egg deposition. As the infection proceeded, egg deposition occurred in more peripheral layers of the intestine as smaller vessels became more constricted from edema and cellular infiltration.

Egg-laying behavior affects the eventual location of eggs in the body and the organs damaged by cell-mediated reactions. Holliman and Fisher (1968) found eggs of Spirorchis scripta in virtually every organ of experimentally infected Chrysemys picta. In addition to the heart and gut wall, eggs were reported from the roof of the mouth, tracheal wall, adipose tissue, brain and spinal cord, connective tissue, and various glands. Similar findings have been reported from marine turtles (Wolke et al., 1982; Glazebrook et al., 1989). In contrast, virtually all reports of egg distribution in Schistosoma spp. infections, natural or experimental, report the overwhelming (typically $>95 \%$ ) number of eggs restricted to the vessels or tissues between the site of deposition and the liver (Hsü and Hsü, 1960; Powers and Cheever, 1972; Cheever and Powers, 1972; Cheever et al., 1974; Chen and Mott, 1988a, 1988b, 1989a, 1989b).

Warren (1978) estimated that approximately $50 \%$ of schistosome eggs fail to exit the host. As noted above, the bulk of these eggs are carried passively to the liver and inevitable destruction. The primary pathology associated with schistosome infections in humans results from those eggs that are trapped in the liver (Farid, 1993; Chen, 1993; Lambertucci, 1993). Whereas schistosome-derived interference with the filtering action of the liver may have serious, long-term consequences for the host, in the short term, the host remains active while the schistosomes continue to deposit additional eggs in the venous system, and at least some fraction of these eggs escape into the external environment. Even in heavy infections, with the development of collateral circulation to bypass the obstructed liver, the eggs collect in the lungs, another organ that can withstand significant assault before failing. It is rare to find schistosome eggs in other, more sensitive, sites. In the exception that proves the rule, the only arterial dwelling species, $D$. pulverulenta, demonstrated different distributions and egg-laying patterns in "normal" and "abnormal" avian hosts (Vande Vusse, 1979). In abnormal hosts, adult worms were found in scattered locations within the arterial system and produced few eggs that typically failed to embryonate and were found in a wide range of tissues. In normal hosts, a higher percentage of worms were found near the origin of the inferior mesenteric artery. The fact that in "normal" hosts eggs were restricted to the mucosa of the posterior $3 / 4$ of the large intestine suggested that females migrated into the inferior mesenteric artery to deposit eggs (Vande Vusse, 1979). The eggs of this species are, therefore, locally restricted to the submucosa, where pathogenesis is unlikely to result in the immediate demise of the host.

Sequestering eggs in schistosome infections is clearly of benefit to the parasite. The wider dispersal of eggs in spirorchid infections may also be beneficial to the parasite. Because the turtles that harbor these parasites are wholly, or mostly, aquatic, the death of a heavily parasitized animal may aid in transmission. Holliman (1971) speculated that predation of heavily infected turtles or scavenging of dead animals might be a primary mechanism for egg dispersal. One of us has dissected numerous small painted turtles $(C$. picta) whose lungs, heart, intestinal tract, brain, and other organs contained massive numbers of eggs (T. Platt, unpubl. obs.). It is difficult to believe that these 
animals could survive to adulthood. A similarly infected mammal would be unlikely to be killed or scavenged where the eggs would reach a suitable habitat for transmission. Aquatic mammals (e.g., muskrats) and birds might provide a similar source for transmission for schistosomes. Although experimental studies of this question are lacking, the undeveloped eggs of spirorchids seem more likely to survive passage in the digestive tract of a predator or scavenger than would the fully embryonated eggs of schistosomes.

\section{ONE PATH TO DIOECY}

Heterochrony in gene expression (either paedomorphosis or peramorphosis; see Brooks and McLennan, 1993c) could have produced protogyny or protandry with the eventual suppression of the subordinate gender, resulting in the establishment of separate sexes (Popiel, 1986; Basch, 1991). Protandry is a widespread, and apparently plesiomorphic (ancestral), characteristic of digeneans (and indeed, of most neodermatans). Once again, ancient evolutionary events may have set the table for the emergence of dioecy in schistosomes; there is clearly a genetic mechanism for suppressing the expression of female gonads, at least for some time. The recent discovery of Uterotrema burnsi/ Uterotrema kreffti (Spirorchidae) from the Australian freshwater turtle, Emydura krefftii, in northern Queensland (Platt and Blair, 1996) suggests that the initial dimorphism may have originated in the spirorchids. Although described as separate taxa, these forms may represent a single, androdioecious species. The slender $U$. burnsi appears to be a fully functional hermaphrodite with sperm in the seminal receptacle and seminal vesicle numerous uterine eggs. The more robust $U$. kreffit possesses a larger testis and, like the type species Uterotrema australispinosa Platt and Pichelin, 1994, appears to lack uterine eggs. Charnov et al. (1976) presented a mathematically plausible scenario for the transition from hermaphroditism to androdioecy to a dioecious population. The extension of the reproductive life of a hermaphrodite through androdioecy would effectively reduce the male contribution of the remaining hermaphrodites ( $a^{*}$ of Charnov et al., 1976), resulting in a shift of resource allocation in the hermaphrodites toward female function. Després and Maurice (1995) suggested that sexual dimorphism was the driving force in schistosome evolution and that gonorchism was a secondary consequence.

The line of thought presented by Charnov et al. (1976) may provide some insight into 1 possible path to the origins of the dioecious condition. The slender $U$. burnsi establishes a typical digenean infection as a functional hermaphrodite, selectively depositing eggs in the small arterioles (venules?) for passage to the gut and then to the external environment. As the worm ages and grows too large for selective egg deposition, it takes up residence in the heart and extends its reproductive life as a functional male ( $U$. kreffti). Once androdioecy is established, males (older individuals + hermaphrodites) are in excess supply, whereas femaleness (hermaphrodites only) becomes a rare commodity. The transition from androdioecy to gonorchism can be hypothesized in the following scenario adapted from Ridley (1993). A nuclear gene suppressing female function is expressed as the worm attains a size no longer conducive to precision egg deposition. This gene spreads because these "functional males" are more successful at fertilizing newly recruited hermaphrodites and the androdioecious condition becomes established. Heterochrony accelerates gene expression resulting in a population of nearly pure male worms. Egg producing capacity is now at a premium as hermaphrodites, which can produce both eggs and sperm, become rare. Suppression of female reproduction is no longer profitable, and development of a cytoplasmic male sterility factor (male killing gene of Ridley, 1993 ) in the remaining hermaphrodite population reduces male function in the hermaphrodites, directing more energy into egg production (Charnov et al., 1976). Any remaining hermaphrodites would lack both male- and female-suppressing genes and would be competing with pure males and females. Most sperm would possess the female suppressor gene, most eggs would possess the cytoplasmic male sterility factor, and the offspring would then be forced to specialize. The initial trend toward dimorphism is, therefore, associated with a division of labor (Després and Maurice, 1995) related to precision egg deposition. If this scenario is correct, nuclear and cytoplasmic genes suppressing the development of female and male characters should be present in schistosomes. The fact that occasional development of intersex individuals occurs (Basch, 1991) argues that the genetic instructions for development of at least some portion of the subordinate sex survives in these organisms, but expression, as a rule, is repressed. If the $U$. burnsi/U. kreffti complex is an example of androdioecy, and depending on the phylogenetic position of Uterotrema, a similar path may have preceded the separation of the sexes in the schistosomes. Completion of the life cycle of these forms and a rigorous phylogenetic analysis of the spirorchids and schistosomes are necessary to determine if they do indeed represent separate species or a single, dimorphic taxon.

\section{THE FOUNDATIONS OF A RESEARCH PROGRAM}

The evolutionary scenario presented above invokes a number of evolutionary changes predicted to have occurred in a particular sequence phylogenetically. Consequently, portions of the scenario can be tested using phylogenetic methods. In addition, a phylogenetic representation can help illustrate some of the problems inherent in disentangling cause and effect. Consider, for example, the phylogenetic tree shown in Figure 1. This tree represents the relative relationships among the Sanguinicolidae, Spirorchidae, and Schistosomatidae. Six characters significant to our discussion are mapped onto the phylogenetic tree. The plesiomorphic, or ancestral, conditions for all 6 characters are placed at the base of the tree, indicating that they are older than the groups in question. These represent the historical background from which the schistosomes evolved. The characteristics of interest to the scenario presented herein are placed on the branch denoting the Schistosomatidae, indicating that these traits are autapomorphies, traits uniquely evolved within the Schistosomatidae. The trait of primary significance is 'dioecy.' Other traits include 'female body slender,' a prediction of the 'size advantage' hypothesis, 'males and females paired,' a prediction of the gene dispersal and low density hypotheses, 'specialist egg deposition,' the explanation for dioecy given by Maynard Smith in Combes (1991), 'inhabiting homeothermic definitive hosts,' the explanation for dioecy given by Grossman et al. (1981) and Short (1983), and 'inhabiting the venous system,' the explanation for dioecy given by Basch (1991). With 


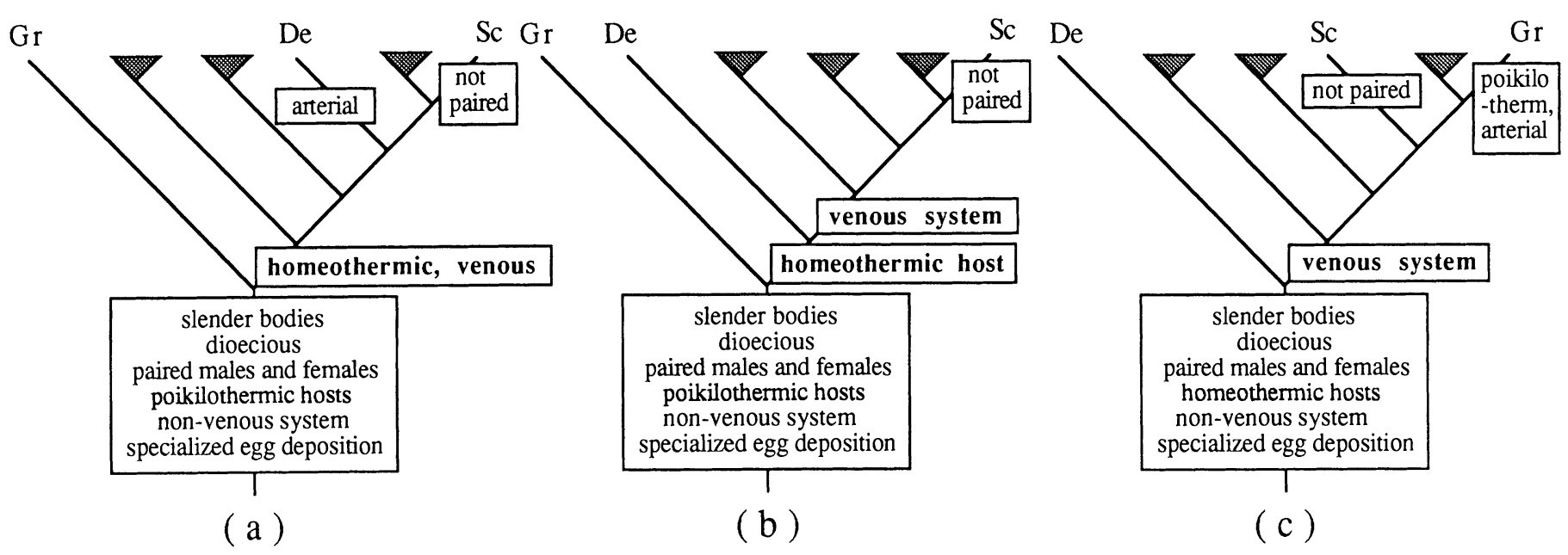

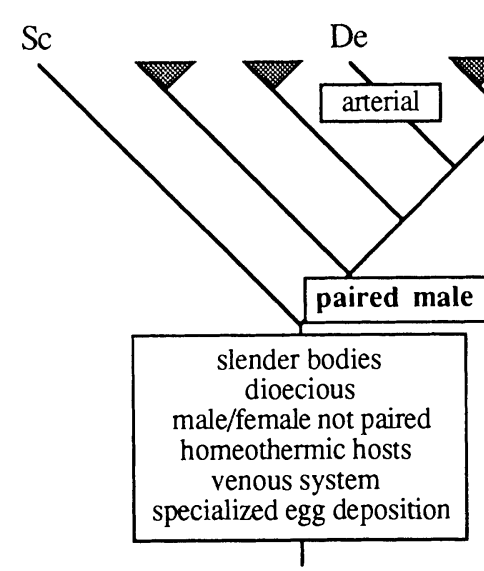

( d )

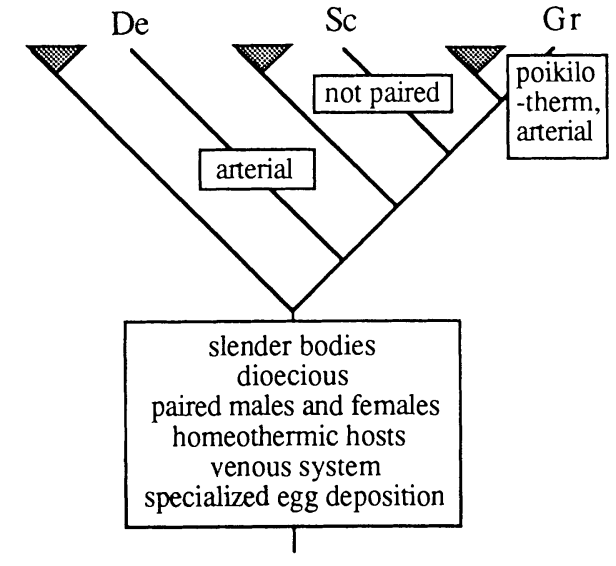

( e )

FIGURE 3. Five hypothetical renderings of phylogenetic relationships among members of the Schistosomatidae. Gr $=$ Griphobilharzia, De $=$ Dendritobilharzia, Sc = Schistosomatium. (a) Griphobilharzia is the sister group of the other schistosomes, and Dendritobilharzia and Schistosomatium are not closely related to it or to each other. (b) Griphobilharzia is the sister group of the other schistosomes, Dendritobilharzia is the next divergent lineage, and Schistosomatium is not closely related to either. (c) Dendritobilharzia is the sister group of the other schistosomes, and Griphobilharzia and Schistosomatium are not closely related to it or to each other. (d) Schistosomatium is the sister group of the other schistosomes, and Griphobilharzia and Dendritobilharzia are not closely related to it or to each other. (e) None of Griphobilharzia, Dendritobilharzia, or Schistosomatium is the sister group of the other schistosomes, and they are not closely related to each other. For each of these scenarios, the box at the base of the tree contains the traits that are best explained as having evolved in the common ancestor of all schistosomes; traits contained in other boxes indicate additional evolutionary changes required to explain the characteristics of the taxa involved. See text for more explanation.

only this level of phylogenetic resolution for the groups involved, it is not possible to identify either transitional states, such as androdioecy, or the sequence in which particular traits evolved. Without information about the sequence of appearance of various traits, we cannot make any inferences about which traits are most fundamental in establishing dioecy. We could equally well conclude that all possible mechanisms contributed to the evolution of dioecy or that we can never determine the causal agent(s). Therefore, the first research project suggested by a comparative approach must be detailed phylogenetic analyses of the members of the Spirorchidae and the Schistosomatidae.

It is important to have completed phylogenetic analysis of the Spirorchidae in order to know if the putatively androdioecious condition found in Uterotrema can be considered ancestral to the dioecious condition found in schistosomes. Figure 2 depicts 2 hypothetical renderings of groupings within the Spirorchidae. If Uterotrema is not the basal member of the Spirorchidae, and if no other spirorchids are androdioecious, then the condition found in Uterotrema has no direct evolutionary connection with the dioecy found in the Schistosomatidae (Fig. $2 a$ ). There are at least 7 other variations of Figure $2 b$, each of which provides different degrees of support for the hypothesis that androdioecy gave rise to dioecy.

It is equally important to have a complete phylogenetic analysis of the Schistosomatidae. Figure 3 depicts 5 different phylogenetic resolutions leading to different explanations of the origins of the various traits considered important in the evolution of dioecy. In every case, dioecy is coupled with specialized egg laying and an unusually slender body form (for females) at the base of the tree, suggesting that these characters, at least, provide the background from which other possibilities evolved. 
If Griphobilharzia is the sister group of the rest of the schistosomes, becoming a specialist in the venous system may have been coupled with the evolution of (or a host switch to) homeothermic hosts (Fig. 3a). If Griphobilharzia, which inhabits a poikilothermic host, is the sister group of all the schistosomes in birds and mammals, and if Dendritobilharzia, which occurs in the arterial system, is the sister group of the remaining schistosomes, becoming a venous specialist evolved after, rather than with, the acquisition of homeothermic hosts (Fig. 3b). In both cases, 'not being paired' is best explained as an evolutionary reversal in Schistosomatium. If Dendritobilharzia, which occurs in the arterial system, is the sister group of the remaining schistosomes, then dioecy evolved in conjunction with slender bodies, paired males and females, homeothermic hosts, and specialized egg deposition; inhabiting the venous system evolved later. Nonpairing in Schistosomatium and inhabiting a poikilothermic host and the arterial system in Griphobilharzia are best explained as evolutionary reversals (Fig. 3c). If Schistosomatium is the sister group of the rest of the schistosomes, inhabiting a homeothermic host and being a venous system specialist evolved along with dioecy, specialized egg laying, and an unusually slender body form (for females) in the common ancestor of the group, and pairing of males and females evolved subsequently; in addition, being an arterial inhabitant (Dendritobilharzia) and having a poikilothermic host (Griphobilharzia) are best explained as evolutionary reversals (Fig. 3d). Finally, if none of Griphobilharzia, Dendritobilharzia, or Schistosomatium is the sister group of the rest of the schistosomes, then inhabiting a homeothermic host, being a venous system specialist, and pairing of males and females evolved along with dioecy, specialized egg laying, and an unusually slender body form (for females) in the common ancestor of the group. In this case, males and females not being paired evolved as an evolutionary reversal in Schistosomatium, having a poikilothermic host evolved as an evolutionary reversal in Griphobilharzia, and being an arterial inhabitant evolved as an evolutionary reversal in Dendritobilharzia (Fig. 3e). This represents the condition shown in Figure 1. As with the depictions in Figure 2, additional scenarios are possible, but these 5 represent the major alternatives possible.

The robustness of phylogenetic analyses is proportional, among other things, to the completeness of knowledge about the group being studied. If there are substantial numbers of spirorchids and schistosomatids still undescribed, it is likely that they, and their phylogenetic relationships, will help illuminate the story of the evolution of schistosomes. The phylogenetic studies, therefore, must be done in conjunction with taxonomic inventories aimed at producing a more complete picture of the actual diversity of digeneans inhabiting the circulatory systems of vertebrates around the world.

In addition to obtaining detailed phylogenetic hypotheses for the Spirorchidae and Schistosomatidae, we must obtain information about the nature of the reproductive cycles for as many spirorchids as possible in order to determine how many are androdioecious and how they are placed on the phylogenetic tree. Then it will be necessary to determine the point of acquisition of homeothermic hosts, being a venous system specialist, pairing of males and females, dioecy, specialized egg laying, and an unusually slender body form (for females). Although this is not an easy task, we hope that we have shown that it is at least possible and have given some guidelines for which taxa and which traits to consider.

\section{ACKNOWLEDGMENTS}

T.R.P. began this work during a sabbatical supported by an Open Fellowship from the Lilly Foundation. T.R.P. thanks David Blair, James Cook University (Australia), for his hospitality during the sabbatical year, his support, and thoughtful discussion. D.R.B. is supported by NSERC Operating Grant A7696. We thank Deborah McLennan, University of Toronto, for preparing the figures.

\section{LITERATURE CITED}

ANDERSON, R. M. 1993. Platyhelminthes-Trematoda. In Reproductive biology of invertebrates, Vol. VI, Part A, K. G. Adiyodi and R. G. Adiyodi (eds.). John Wiley \& Sons, New York, New York, p. 143195.

BASCH, P. F. 1990. Why do schistosomes have separate sexes? Parasitology Today 6: $160-163$.

1991. Schistosomes: Development, reproduction, and host relations. Oxford University Press, New York, New York, 248 p.

BORYSENKO, M. 1978. Lymphoid tissues and cellular components of the reptilian immune system. In Animal models of comparative and developmental aspects of immunity and disease, M. E. Gershwin and E. L. Cooper (eds.). Pergamon Press, New York, New York, p. $63-79$.

Brooks, D. R. 1979. New records for amphibian and reptile trematodes. Proceedings of the Helminthological Society of Washington 46: 286-289.

- S. M. BAndoni, C. A. Macdonald, And R. T. O’Grady. 1989. Aspects of the phylogeny of the Trematoda Rudolphi, 1808 (Platyhelminthes: Cercomeria). Canadian Journal of Zoology 67: 26092624.

2624. AND M. A. MAYES. 1975. Platyhelminthes of Nebraska turtles with descriptions of two new species of spirorchiids (Trematoda: Spirorchiidae). Journal of Parasitology 61: 403-406.

- And D. A. MCLennan. 1991. Phylogeny, ecology, and behavior. University of Chicago Press, Chicago, Illinois, 434 p.

- AND - 1993a. Comparative study of adaptive radiations with an example using parasitic flatworms (Platyhelminthes: Cercomeria). American Naturalist 143: 379-402.

$\longrightarrow$, AND 1993b. Macroevolutionary trends in the morphological diversification among parasitic flatworms (Platyhelminthes: Cercomeria). Evolution 47: 495-509.

$\longrightarrow$, AND —. 1993c. Parascript: Parasites and the language of evolution. Smithsonian Institution Press, Washington, D.C., 429 p. - R. T. O'Grady, and D. R. Glen. 1985. Phylogenetic analysis of the Digenea (Platyhelminthes: Cercomeria) with comments on their adaptive radiation. Canadian Journal of Zoology 63: 411-443.

Brown, H. W., AND F. A. Neva. 1983. Basic clinical parasitology, 5th ed. Appleton-Century-Crofts, Norwalk, Connecticut, 339 p.

BURGGREN, W. W. 1987. Form and function in reptilian circulation. American Zoologist 27: 5-19.

Charnov, E. L., J. Maynard Smith, and J. J. Bull. 1976. Why be a hermaphrodite? Nature 263: 125-126.

Cheever, A. W., D. G. Erickson, E. H. Sadun, and F. von LichtenBERG. 1974. Schistosoma japonicum infection in monkeys and baboons: Parasitological and pathological findings. American Journal of Tropical Medicine and Hygiene 23: 51-64.

, AND K. G. POWERS. 1972. Schistosoma mansoni infection in rhesus monkeys: Comparison of the course of heavy and light infections. Bulletin of the World Health Organization 46: 301-309.

CHEN, M. G. 1993. Schistosoma japonicum and S. japonicum-like infections: Epidemiology, clinical and pathological aspects. In $\mathrm{Hu}-$ man schistosomiasis, P. Jordan, G. Webbe, and R. F. Sturrock (eds.). CAB International Press, Wallingford, U.K., p. 237-270.

, AND K. E. MotT. 1988a. Progress in assessment of morbidity due to Schistosoma japonicum infection-A review of recent literature. Tropical Diseases Bulletin 85(6): 21-R46. 

to Schistosoma mansoni infection-A review of recent literature. Tropical Diseases Bulletin 85(10): R1-R56.

- AND - 1989a. Progress in assessment of morbidity due to Schistosoma haematobium infection-A review of recent literature. Tropical Diseases Bulletin 86(4): R1-R36.

$\longrightarrow$, AND $\longrightarrow$. 1989b. Progress in assessment of morbidity due to Schistosoma intercalatum infection-A review of recent literature. Tropical Diseases Bulletin 86(8): R1-R18.

ClaRK, W. C. 1978. Hermaphroditism as a reproductive strategy for metazoans; some correlated benefits. New Zealand Journal of Zoology 5: 769-780.

Combes, C. 1991. The schistosome scandal. Acta Oecologica 12: 165173.

DAmiAn, R. T. 1987. The exploitation of host immune responses by parasites. Journal of Parasitology 73: 3-13.

DesPrÉs, L., AND S. MAURICE. 1995. The evolution of dimorphism and separate sexes in schistosomes. Proceedings of the Royal Society (London) 262: 175-180.

FARID, Z. 1993. Schistosomes with terminal-spined eggs: Pathological and clinical aspects. In Human schistosomiasis, P. Jordan, G. Webbe, and R. F. Sturrock (eds.). CAB International Press, Wallingford, U.K., p. 155-193.

FILE, S. 1995. Interaction of schistosome eggs with vascular endothelium. Journal of Parasitology 81: 234-238.

FRIED, B. 1986. Chemical communication in hermaphroditic digenetic trematodes. Journal of Chemical Ecology 12: 1659-1677.

Fulford, A. J. C., A. E. Butterworth, J. H. Ouma, And R. F. SturROCK. 1995. A statistical approach to schistosome population dynamics and estimation of the life-span of Schistosoma mansoni in man. Parasitology 110: 307-316.

GanONG, W. F. 1983. Review of medical physiology, 11th ed. Lange Medical Publications, Los Altos, California, 643 p.

GHISELIN, M. T. 1969. The evolution of hermaphroditism among animals. Quarterly Review of Biology 44: 189-208.

Glazebrook, J. S., R. S. F. Campbell, and D. Blair. 1989. Studies on cardiovascular fluke (Digenea: Spirorchiidae) infections in sea turtles from the Great Barrier Reef, Queensland, Australia. Journal of Comparative Pathology 101: 231-250.

GoodChiLD, G. C., AND E. S. DENNIS. 1967. Comparative egg counts and histopathology in turtles infected with Spirorchis (Trematoda: Spirorchiidae). Journal of Parasitology 53: 38-45.

, AND D. E. KIRK. 1960. The life cycle of Spirorchis elegans Stunkard, 1923 (Trematoda: Spirorchiidae) from the painted turtle. Journal of Parasitology 46: 219-229.

Greiner, E. C., D. J. Forrester, AND E. R. JACOBSON. 1980. Helminths of mariculture-reared green turtles (Chelonia mydas mydas) from Grand Cayman, British West Indies. Proceedings of the Helminthological Society of Washington 47: 142-144.

Grossman, A. I., R. B. ShORT, AND G. D. Cain. 1981. Karyotype evolution and sex chromosome differentiation in schistosomes (Trematoda, Schistosomatidae). Chromosoma 84: 413-430.

Holliman, R. B. 1971. Ecological observations on two species of spirorchid trematodes. American Midland Naturalist 86: 509-512.

- AND J. E. FISHER. 1968. Life cycle and pathology of Spirorchis scripta Stunkard, 1923 (Digenea: Spirorchiidae) in Chrysemys picta picta. Journal of Parasitology 54: 310-318.

,, 1 AND J. C. PARKER. 1971. Studies on Spirorchis parvus (Stunkard, 1923) and its pathological effects on Chrysemys picta picta. Journal of Parasitology 57: 71-77.

Hsü, H. F., AND S. Y. LI Hsü. 1960. Distribution of eggs of different geographic strains of Schistosoma japonicum in the viscera of infected hamsters and mice. American Journal of Tropical Medicine and Hygiene. 9: 240-247.

Jensen, R. J. 1996. BIOSTATS, version 1.0. Saint Mary's College, Notre Dame, Indiana.

Johnson, R. B. 1986. Human disease and the evolution of pathogen virulence. Journal of Theoretical Biology 122: 19-24.

JURD, R. D. 1994. Reptiles and birds. In Immunology: A comparative approach, R. J. Turner (ed.). John Wiley \& Sons, New York, New York, p. 137-172.

LAMBERTUCCI, J. R. 1993. Schistosoma mansoni: Pathological and clinical aspects. In Human schistosomiasis, P. Jordan, G. Webbe, and
R. F. Sturrock (eds.). CAB International Press, Wallingford, U.K., p. $195-235$.

McLennan, D. A. 1996. Integrating phylogenetic and experimental analyses: The evolution of male and female nuptial coloration in stickleback fishes (Gasterosteidae). Systematic Biology 45: 261277.

Minchella, D. J., K. M. Sollenberger, and C. Pereira de Souza. 1995. Distribution of schistosome genetic diversity within molluscan intermediate hosts. Parasitology 111: 217-220.

Morand, S., J.-P. Pointier, G. Borel, and A. Théron. 1993. Pairing probability of schistosomes related to their distribution among the host population. Ecology 74: 2444-2449.

Nollen, P. M. 1983. Patterns of sexual reproduction among parasitic platyhelminths. Parasitology 86: 99-120.

Overstreet, R. M., AND J. ThULIN. 1989. Response by Plectropomus leopardus and other serranid fishes to Personellum corventum (Digenea: Sanguinicolidae), including melanomacrophage centres in the heart. Australian Journal of Zoology 37: 129-142.

PlatT, T. R. 1993. Taxonomic revision of Spirorchis MacCallum, 1919 (Digenea: Spirorchidae). Journal of Parasitology 79: 337-346.

$\longrightarrow$, AND D. BLAIR. 1996. Two new species of Uterotrema (Digenea: Spirorchidae) parasitic in Emydura krefftii (Testudines: Chelidae) from Australia. Journal of Parasitology 82: 307-311.

,-- J. PuRdie, AND L. Melville. 1991. Griphobilharzia amoena n. gen., n. sp. (Digenea: Schistosomatidae), a parasite of the freshwater crocodile Crocodylus johnstoni (Reptilia: Crocodylia) from Australia, with the erection of a new subfamily, Griphobilharziinae. Journal of Parasitology 77: 65-68.

PopieL, I. 1986. The reproductive biology of schistosomes. Parasitology Today 2: 10-15.

Powers, K. G., AND A. W. CheEver. 1972. Comparison of geographical strains of Schistosoma mansoni in the rhesus monkey. Bulletin of the World Health Organization 46: 295-300.

Read, A. F., AND S. NeE. 1990. Male schistosomes: More than just muscle (letter to the editor). Parasitology Today 6: 297.

Ridley, M. 1993. The red queen: Sex and the evolution of human nature. Penguin Books, New York, New York, 405 p.

ShorT, R. B. 1983. Sex and the single schistosome. Journal of Parasitology 69: 4-22.

SмIтH, J. W. 1972. The blood flukes of cold-blooded vertebrates and some comparison with the schistosomes. Helminthological Abstracts, Series A 41: 161-204.

Southgate, V. R., L. A. TChuem Tchuenté, J. Vercruysse, and J. JOURDANE. 1995. Mating behaviour in mixed infections of Schistosoma haematobium and S. mattheei. Parasitology Research 81: 651-656.

STUNKARD, H. W. 1923. Studies on North American blood flukes. Bulletin of the American Museum of Natural History 48: 165-221.

TChuem Tchuenté, L. A., D. Imbert-Establet, V. R. Southgate, And J. JOURDANE. 1994. Interspecific stimulation of parthenogenesis in Schistosoma intercalatum and S. mansoni. Journal of Helminthology 68: 167-173.

, V. R. Southgate, D. Imbert Establet, and J. Jourdane. 1995. Change of mate and mating competition between males of Schistosoma intercalatum and S. mansoni. Parasitology 110: 4552.

Théron, A., J. P. Pointier, S. Morand, D. Imbert-Establet, and G. BOREL. 1992. Long-term dynamics of natural populations of Schistosoma mansoni among Rattus rattus in patchy environment. Parasitology 104: 291-298.

Tizzard, I. R. 1992. Immunology, 3rd ed. Saunders College Publishing, New York, New York, 527 p.

Ulmer, M. J. 1959. Studies on Spirorchis haematobium (Stunkard, 1922) Price, 1934 (Trematoda: Spirorchiidae) in the definitive host. Transactions of the American Microscopical Society 78: 81-89.

VANDE VuSSE, F. J. 1979. Host-parasite relations of Dendritobilharzia pulyerulenla (Trematoda: Schistosomatidae) and anatids. Journal of Parasitology 65: 894-897.

WALL, L. D. 1941a. Life history of Spirorchis elephantis (Cort, 1917), a new blood fluke from Chrysemys picta. American Midland Naturalist 25: 402-411.

-1941b. Spirorchis parvus (Stunkard) its life history and the 
development of its excretory system (Trematoda: Spirorchiidae). Transactions of the American Microscopical Society 60: 221-260.

. 1951. Life history of Vasotrema robustum (Stunkard, 1928) Trematoda: Spirorchiidae. Transactions of the American Microscopical Society 70: $173-184$.

WARREN, K. S. 1978. The pathology, pathobiology and pathogenesis of schistosomiasis. Nature 273: 609-612.

Wolke, R. E., D. R. BRoOKS, AND A. GeORGe. 1982. Spirorchidiasis in loggerhead sea turtles (Caretta caretta): Pathology. Journal of Wildlife Diseases 18: 175-185.

WoOD, L. M., AND W. J. BACHA, JR. 1983. Distribution of eggs and the host response in chickens infected with Austrobilharzia variglandis (Trematoda). Journal of Parasitology 69: 682-688.
Wu, G. Y., AND C. H. Wu. 1986. Portal serum constituents: Possible determinants for anatomical localization of Schistosoma mansoni during maturation and reproduction. Journal of Chemical Ecology 12: $1797-1803$.

YAMAGUTI, S. 1971. Synopsis of digenetic trematodes of vertebrates. Keigaku Publishing Co., Tokyo, Japan, 1,074 p.

- 1975. Synoptical review of life histories of digenetic trematodes of vertebrates. Keigaku Publishing Co., Tokyo, Japan, 1,110 p.

Zapata, A. G., A. VARAS, AND M. TORROBA. 1992. Seasonal variations in the immune system of lower vertebrates. Immunology Today 13: 142-147. 